\title{
Images: Ruptured intratesticular arteriovenous malformation
}

Mario Capitano $^{1}$; Nicola Schieda ${ }^{2}$; Susan J. Robertson ${ }^{1}$; Chris Morash ${ }^{3}$; Rodney H. Breau ${ }^{3}$; Conrad Maciejewski ${ }^{3}$; Trevor A. Flood ${ }^{1}$

${ }^{1}$ Department of Pathology \& Laboratory Medicine; ${ }^{2}$ Department of Medical Imaging; ${ }^{3}$ Department of Urology; The Ottawa Hospital, Ottawa, ON, Canada

Cite as: Can Urol Assoc J 2018 June 8; Epub ahead of print. http://dx.doi.org/10.5489/cuaj.5049

Published online June 8, 2018

The majority of intratesticular masses in men 20-40 years old are malignant germ cell tumours. Although rare, there are several benign entities that also must be considered in the differential diagnosis including orchitis, hematomas, and vascular neoplasms. ${ }^{1}$ Arteriovenous malformations (AVMs) are benign vascular lesions that rarely occur in the testicle. The pathogenesis of intratesticular AVMs may be congenital or post-traumatic. ${ }^{2}$ These benign lesions typically present as painless, non-palpable masses and are usually detected incidentally during the workup for infertility. ${ }^{3}$ Intratesticular AVMs are associated with characteristic colour Doppler ultrasound and dynamic contrast MRI features. Most reported cases have been managed conservatively although surgery may be indicated if the patient is symptomatic. $^{2}$

A healthy 37 year old man presented to the emergency department with sudden onset of nausea and severe left sided scrotal pain with associated swelling. He had no previous history of similar episodes and he reported an absence of testicular trauma or lower urinary tract symptoms. Medical, social, and family histories were non-contributory. Physical examination revealed a swollen and tender left testicle. A palpable mass was not appreciated and the remainder of the examination was unremarkable. Serum testicular cancer markers (LDH, AFP, and beta-hCG) were within normal limits. The patient was sent for urgent ultrasound for further characterization. Grey scale ultrasound images depicted a 1.7 x $1.6 \mathrm{x}$ $1.5 \mathrm{~cm}$ heterogeneously hyperechoic mass extending from the interpolar to upper polar regions of the testicle. The majority of the mass showed no internal flow on colour and power Doppler techniques except for a minute peripheral hypoechoic component. Pulsed Doppler showed low resistive arterial flow (Fig. 1). The urology team reviewed the imaging and felt that a malignant neoplasm could not be fully excluded. The patient consented to a radical orchiectomy if there were no intraoperative signs of testicular torsion. Surgery was routine and there were no additional findings. The specimen was sent to pathology for examination. Gross examination of the radical orchiectomy specimen showed a testis measuring 5.7 x $4.7 \mathrm{x}$ $1.5 \mathrm{~cm}$. The external surface was unremarkable. On cut surface there was a $2.2 \times 1.8$ x 1.5 
$\mathrm{cm}$ red-brown mass that was suggestive of clotted blood. The mass was located adjacent to the tunica albuginea and opposite of the epididymis. The remainder of the testicle was unremarkable. The lesion was entirely submitted for microscopic examination (Fig. 2). Slides showed areas of recent hemorrhage that were compressing the seminiferous tubules. There was a focus of arteries and distended thin walled veins that were intimately associated with the area of hemorrhage. There was no cellular atypia and germ cell neoplasia in situ was absent. The findings were consistent with a recently ruptured intratesticular AVM with associated hemorrhage.

Intratesticular AVMs are extremely rare and benign vascular lesions. They tend to be $<10$ $\mathrm{mm}$ in greatest dimension and are composed of complex jumbles of dilated arteries and veins without intervening capillaries. AVMs typically are not painful and tend to be detected incidentally during the evaluation for infertility. ${ }^{3}$ In this report the patient presented with severe scrotal pain of sudden onset. An intratesticular AVM presenting with pain has been reported once before in the literature where the discomfort was described as recurrent and chronic in nature, ${ }^{4}$ rather than acute as in this report. The most common disease processes that present with acute scrotal pain include testicular torsion, epididymo-orchitis, and occasionally germ cell tumours when there is associated intra-lesional hemorrhage or infarction. ${ }^{5,6}$ The symptoms of pain that are sometimes associated with intratesticular AVMs has been hypothesized to be secondary to ischemia. This occurs because of the absence of capillaries that exist between tangled arteries and veins. This lack of capillaries allows blood travelling between the arteries and veins to flow rapidly under high pressure with subsequent bypassing of the target tissue, leading to ischemic changes and subsequent pain. ${ }^{4}$ In regard to our patient, the cause of the acute nature of the pain was likely due to the sudden rupture of the AVM with subsequent mass effect secondary to haemorrhage.

The previously reported cases of intratesticular AVMs are described as being hypoechoic and solid on grey scale ultrasound. ${ }^{3,7,8}$ These grey scale findings are relatively nonspecific and can be seen in both malignant and benign lesions. ${ }^{9}$ Notably, the mass in our case was hyperechoic on sonography, in retrospect, due to the large amount of hemorrhage associated with the ruptured AVM. Numerous lesions can be hyperechoic on ultrasound including teratomas, epidermoid cysts, and "burnt out" germ cell tumours. ${ }^{10,11}$ Colour Doppler ultrasound can frequently aid in the identification of AVMs and typically shows prominent vessels throughout the mass with low resistive high velocity bidirectional flow. Occasionally, the presence of a feeding artery and draining vein may be identified. ${ }^{3,8}$ Our case lacked the characteristic ultrasound features because the minute AVM had ruptured and was associated with a large amount of pooling intratesticular haemorrhage that lacked blood flow. Additionally, the large amount of haemorrhage also helps to account for the lesion's relatively large size given that intratesticular AVMs tend to be less than one centimeter in greatest dimension. ${ }^{1}$ Although not used in the current case, dynamic contrast MRI examination can 
help demonstrate the lesion's vascular nature and shows early and intense enhancement. Serpiginous structures indicative of the feeding vessels may also be identified. ${ }^{3}$

In conclusion, intratesticular AVMs are extremely rare benign vascular lesions with only a handful of cases reported in the literature. Their clinical presentation can be variable although typically they are painless non-palpable masses that are detected incidentally. Colour Doppler ultrasound and dynamic contrast MRI can highlight the lesion's vascular nature and the presence of a feeding artery with draining vein. In the current case, rupture of the intratesticular AVM with associated hemorrhage clouded some of the expected clinical features usually seen with these lesions. 


\section{References}

1. Gulsen F, Mihmanli I, Kantarci F, Eren A, Ataus SO. Testicular arteriovenous malformation: gray-scale and color Doppler ultrasonography features. Case reports in medicine 2011;2011:876206.

2. Bhatt S, Jafri SZ, Wasserman N, Dogra VS. Imaging of non-neoplastic intratesticular masses. Diagnostic and interventional radiology (Ankara, Turkey) 2011;17:52-63.

3. Skiadas V, Antoniou A, Primetis H, Moulopoulos L, Vlahos L. Intratesticular arteriovenous malformation. Clinical course, ultrasound and MRI findings of an extremely rare lesion on a 7 year follow-up basis. International urology and nephrology 2006;38:119-22.

4. Sountoulides P, Bantis A, Asouhidou I, Aggelonidou H. Arteriovenous malformation of the spermatic cord as the cause of acute scrotal pain: a case report. Journal of medical case reports 2007;1:110.

5. Dogra V, Bhatt S. Acute painful scrotum. Radiologic clinics of North America 2004;42:349-63.

6. Carver BS, Sheinfeld J. Germ cell tumors of the testis. Annals of surgical oncology 2005;12:871-80.

7. Bhatt S, Rubens DJ, Dogra VS. Sonography of benign intrascrotal lesions. Ultrasound quarterly 2006;22:121-36.

8. Kutlu R, Alkan A, Soylu A, Sigirci A, Dusak A. Intratesticular arteriovenous malformation: color Doppler sonographic findings. Journal of ultrasound in medicine : official journal of the American Institute of Ultrasound in Medicine 2003;22:295-8.

9. Ma W, Sarasohn D, Zheng J, Vargas HA, Bach A. Causes of Avascular Hypoechoic Testicular Lesions Detected at Scrotal Ultrasound: Can They Be Considered Benign? AJR American journal of roentgenology 2017;209:110-5.

10. Woodward PJ, Sohaey R, O'Donoghue MJ, Green DE. From the archives of the AFIP: tumors and tumorlike lesions of the testis: radiologic-pathologic correlation. Radiographics : a review publication of the Radiological Society of North America, Inc 2002;22:189-216.

11. Rocher L, Ramchandani P, Belfield J, et al. Incidentally detected non-palpable testicular tumours in adults at scrotal ultrasound: impact of radiological findings on management Radiologic review and recommendations of the ESUR scrotal imaging subcommittee. European radiology 2016;26:2268-78. 
Figures and Tables

Fig. 1. Pulsed Doppler showing low resistive arterial flow.
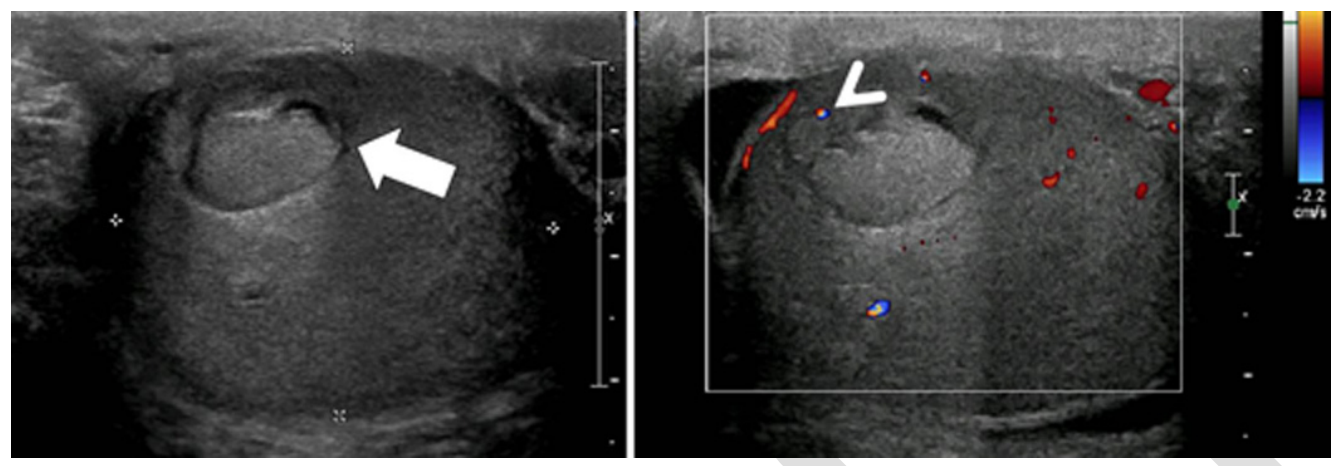

Fig. 2. Microscopic examination of the lesion.
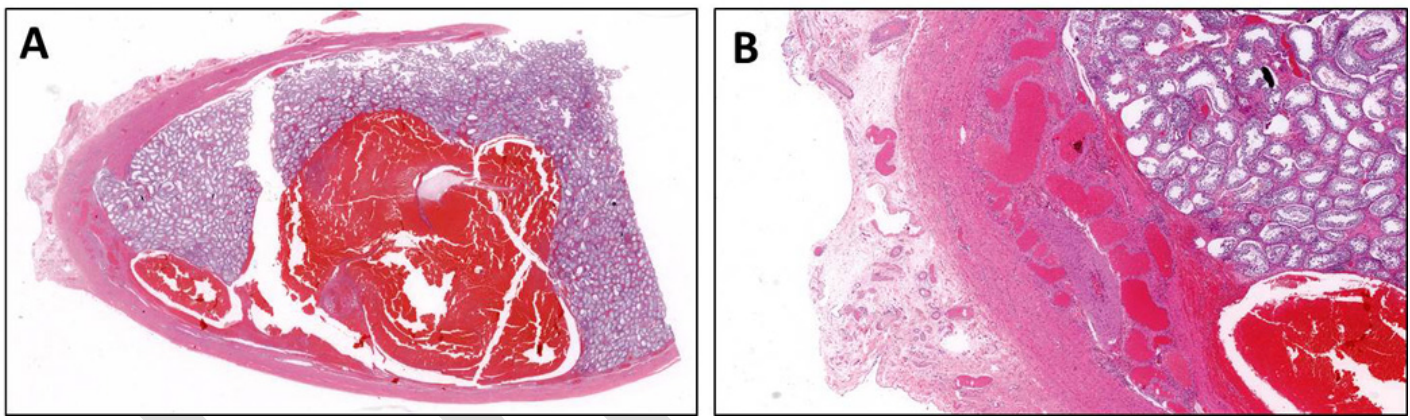